\title{
Is neutrophil gelatinase-associated lipocalin unaffected by convective continuous renal replacement therapy? Definitely ... maybe
}

\author{
Patrick M. Honore*, Rita Jacobs, Inne Hendrickx, Elisabeth De Waele, Viola Van Gorp and Herbert D. Spapen \\ See related research by Schilder et al., http://www.ccforum.com/content/18/2/R78; and Vasileiadis et al., http://www.ccforum.com/content/19/1/140
}

Two recent studies published in Critical Care reported that plasma [1] and urinary [2] levels of neutrophil gelatinase-associated lipocalin (NGAL), an important biomarker for prediction and diagnosis of acute kidney injury, were not affected by continuous renal replacement therapy (CRRT).

The investigators assessed NGAL elimination during continuous venovenous hemofiltration [1] and hemodiafiltration [2] using respectively a cellulose triacetate [1] and a polysulfone [2] membrane filter. Of note is that these filters both have notoriously low adsorption capacity [3]. Recently, the proinflammatory high-mobility group box 1 protein, a cytokine with a molecular weight approximating that of NGAL, was also found to be unaffected by convective CRRT. However, it was significantly (up to $90 \%$ !) cleared from the circulation when highly adsorptive membranes (i.e., surface-treated acrylonitrile 69 and polymethylmethacrylate) were used [4].

These membranes are increasingly applied for hemofiltration in critically ill patients [4]. Thus, it is imperative to evaluate NGAL clearance during convective CRRT performed with highly adsorptive membranes before definitively accepting that CRRT leaves the sensitivity of this biomarker intact.

\section{Abbreviations}

CRRT: Continuous renal replacement therapy; NGAL: Neutrophil

gelatinase-associated lipocalin.

\section{Competing interests}

The authors declare that they have no competing interests.

Published online: 17 November 2015
References

1. Schilder L, Nurmohamed SA, ter Wee PM, Paauw NJ, Girbes AR, Beishuizen A, et al. The plasma level and biomarker value of neutrophil gelatinase-associated lipocalin in critically ill patients with acute kidney injury are not affected by continuous venovenous hemofiltration and anticoagulation applied. Crit Care 2014;18:R78

2. Vasileiadis I, Pipili C, Nanas S. Continuous renal replacement therapy in critically ill patients does not affect urinary neutrophil gelatinase-associated lipocalin levels. Crit Care. 2015;19:140.

3. Honore PM, Jacobs R, Joannes-Boyau O, De Regt J, De Waele E, van Gorp V, et al. Newly designed CRRT membranes for sepsis and SIRS - a pragmatic approach for bedside intensivists summarizing the more recent advances: a systematic structured review. ASAIO J. 2013;59:99-106.

4. Yumoto $M$, Nishida O, Moriyama $K$, Shimomura $Y$, Nakamura T, Kuriyama $N$, et al. In vitro evaluation of high mobility group box 1 protein removal with various membranes for continuous hemofiltration. Ther Apher Dial. 2011;15:385-93.

* Correspondence: Patrick.Honore@az.vub.ac.be

ICU Department, Universitair Ziekenhuis Brussel, Vrije Universiteit Brussel, 101 Laarbeeklaan, 1090 Jette, Brussels, Belgium 